\title{
Rethinking sustainable urban regeneration: ambiguity, creativity, and the shared territory
}

\section{James Evans, 9 Phil Jones}

School of Geography, Earth and Environmental Sciences, University of Birmingham, Edgbaston, Birmingham B15 2TT, England; e-mail: p.i.jones@bham.ac.uk

Received 4 November 2005; in revised form 5 September 2006; published online 29 August 2007

\begin{abstract}
Despite its broad definition, the concept of sustainability has become central to regeneration policy in the UK. A growing body of research, however, suggests that the policy goals of urban regeneration and sustainable development are not being integrated in practice. Ambiguity surrounding what 'sustainability' actually means is often cited as the reason why projects fail to achieve policy goals. We seek to make an innovative contribution to this debate, arguing that sustainability does make a positive difference in practice, and that it is necessary to develop approaches that capture these 'actually existing sustainabilities'. Using a detailed case study of a multistakeholder regeneration project, we develop a more positive analysis of the role which ambiguity plays in the development process. We advance a dialogic conception of sustainability based upon Michel Bakhtin's sociolinguistic theory of the word as a 'shared territory'. We suggest that the notion of sustainability acts as a shared territory for meaning around which diverse stakeholder groups coalesce, and show how the ambiguity inherent in this shared conception can generate more creative (and sustainable) outcomes to developmental challenges. Viewing sustainability as a shared territory makes ambiguity not only intelligible, but also desirable to the development process, and it is argued that there is a need to avoid the reduction of sustainability to the assessment of predetermined benchmarks or policy goals, both within the regeneration literature and across studies of planning policy and practice more generally.
\end{abstract}

\section{Introduction}

Sustainability has been placed at the core of UK regeneration strategies (DETR, 2000a; ODPM, 2003; 2005a) with the newly created Department for Communities and Local Government using the phrase 'creating sustainable communities' as its overarching mission statement. The holistic approach to regeneration implied by the term 'sustainable' fits neatly with agendas of inclusiveness, multiagency partnerships, and the shift from government to governance that have been pursued with great enthusiasm since the election of the ('New') Labour government in 1997 (Newman, 2001; Pierre, 2000; Rhodes, 1997; Stoker, 2000). But despite this apparent compatibility, a growing body of research suggests that the policy goals of urban regeneration and sustainable development are not being integrated in practice (Couch and Denneman, 2000).

'Sustainability' is a term with somewhat fluid meanings. A tripartite conception of sustainability-blending economic, social, and environmental factors - is generally accepted in the literature (Carley and Christie, 1992; Rydin et al, 2003; Whitehead, 2003). In terms of sustainable development this holistic conception has led to a great deal of debate and tension over the weighting given to each of the three components (for example Gibbs and Jonas, 2000; Roseland, 2000). The result has been a certain amount of ambiguity over what a sustainable development looks like in practice. Different agents in the regeneration process have been able to use this uncertainty to place greater emphasis on one or other of the constituent components of 'sustainable' development. Theoretical analyses of sustainable regeneration have, therefore, tended to cast ambiguity as a barrier to successful holistic redevelopment (Astleithner et al, 2004; Davies, 2002a). 
The flexibility of 'sustainability' has allowed practitioners, at least in part, to emphasise that part of the agenda that fits with their own-developers, for instance, looking for an economically sustainable (aka 'viable') project. The language of 'paying lip service' and 'ticking boxes' all too often suggests that policies promoting sustainability have little or no impact upon the form a development takes. But although 'the concept remains elusive and even treacherous... it is a fertile concept' (Prugh et al, 2000, page xiii, emphasis added), and alongside these critiques others have viewed the lack of definition positively, as having the potential to initialise a discourse (University of Aberdeen and Kevin Murray Associates, 2004). It is our contention that the notion of sustainability does make a positive difference to urban regeneration projects, even if it is not always the intended one. In the following paper we aim to capture this difference.

We begin by outlining the (familiar) debate concerning what 'sustainability' and 'sustainable development' could and should mean, and then outline the work of three recent studies that have highlighted how ambiguity undermines the sustainability of developments in different ways. A common theme that emerges is the perceived failure of collaborative planning and public-private partnerships to achieve consensus and deliver the triple bottom line of sustainability in urban regeneration projects. Although this undoubtedly often is the case, analyses that judge projects against abstract academic benchmarks and/or policy indicators miss the difference which sustainability makes as it happens in practice. This is the unavoidably grounded, unreflexive, emergent, and often accidental element of sustainability; what Krueger and Agyeman (2005) have termed 'actually existing sustainabilities'. It is this aspect of sustainability that too often falls through the cracks of formal political and institutional theoretical frameworks.

In order to develop an alternative theoretical register with which to articulate the role of ambiguity we advance a dialogic conception of sustainability, based upon Michel Bakhtin's sociolinguistic theory of the word as a 'shared territory'. By conceiving meaning as the product of social interaction between different actors, this approach recognises that dialogue is always based upon a partially shared understanding of a word. We explore this phenomenon through a detailed case study of a flagship project to regenerate a run-down inner-city estate in Birmingham, UK. Drawing upon qualitative interview material with both the central and the peripheral players in this project, we reflect upon how they talk about sustainability and how this talk shapes the subsequent urban regeneration partnership. We suggest that the notion of sustainability acts as a 'shared territory' for meaning around which diverse stakeholder groups coalesce. Furthermore, we argue that the ambiguity inherent in this shared conception generated a more creative (and sustainable) outcome to the developmental challenges of the project.

In the conclusion we consider how different communicative approaches to urban regeneration capture different aspects of what is an inherently multifaceted political process, and attempt to outline how the analysis offered fits with more institutional accounts. This task is of particular importance in situating our own, rather positive, account of ambiguity and the regeneration process, in terms both of broader poststructural approaches to planning, and of the wider relevance of academic research to the sustainability agenda.

\section{Sustainable development and regeneration}

There is a substantial literature dealing with how the principles of sustainable development are articulated at various levels of governance. Although we acknowledge this literature on subsidiarity, our focus is upon how these principles are delivered in practice through the partnerships that characterise collaborative planning (Healey, 1997). It is the 
supposed failures of collaborative planning to deliver sustainability in regeneration that provides the departure for our own theoretical reworking of a communicative theory of sustainability.

The World Commission on Environment and Development (WCED) identified sustainable development as that which "meets the needs of the present without compromising the ability of future generations to meet their own needs" (WCED, 1987, page 43). Since the WCED report considerable effort has gone into exploring and attempting to refine the concept, and the complexities surrounding the various conceptual and historical antecedents and forebears of sustainable development have generated a literature in their own right (Mebratu, 1998; Pezzoli, 1997). A common understanding of the term in policy is linking economic, social, and environmental concerns to form the so-called 'triple bottom line' (Pope et al, 2004).

Given this definition, some commentators feel that the term has become so inclusive as to be almost meaningless: as Priemus (2005, page 5) wryly notes, "Sustainability is profit, people and planet at the same time; it seems to mean something like happiness." For example, the 'weak' versus 'strong' sustainability debate, which was particularly active during the 1990s, turned on the emphasis given to environmental protection, with weak sustainability, stressing the social dimension (Gibbs et al, 1998; Jamieson, 1998). The whole question of the degree to which environmental 'goods' could be considered substitutable in weak sustainability (Gutes, 1996) reflected the ideological divide inherent in such an inclusive/elusive concept (Gibbs et al, 1998).

The land-use planning system has come under considerable scrutiny as a core mechanism for the delivery of sustainable development (Bruff and Wood, 2000; Owens and Cowell, 2002; Rydin, 1998). As Owens points out, "planning and sustainability share two fundamental perspectives - the temporal and the spatial. Both are concerned with future impacts on and of particular localities" (1994, page 440 quoted by Murdoch, 2006, page 151). With the publication in February 2003 of the document Sustainable Communities: Building for the Future, the government installed sustainability as the cornerstone of UK planning policy (ODPM, 2003; 2005a; Raco, 2003). In its most recent iteration, five key elements of sustainability are identified in relation to the planning system: social cohesion and inclusion; protection and enhancement of the natural environment; prudent use of natural resources; sustainable economic growth; and the integration of sustainable development in development plans (ODPM, 2005b). In addition to the process of development planning, these goals are delivered through Local Strategic Partnerships (LSPs), which bring together the public, private, business, community, and voluntary sectors in order to address initiatives and services within local areas. Although these partnerships echo LA21 in terms of their nonstatutory basis, they are central in drawing up Local Area Agreements, which set out the priorities for a local area agreed between central government and other key partners at the local level over a three-year period. These agreements are critical in accessing central government funding (CLG, 2006).

The strategic aims of urban regeneration are amenable to the goals of sustainable development in key ways. At the most basic level, the reuse of derelict land and the associated rejuvenation of impoverished areas can be viewed as sustainable (Couch and Denneman, 2000). Similarly, large-scale projects that entail the spatiotemporal extension of traditional planning functions across a range of organisations should offer scope for achieving the joined-up thinking that the integrative aspirations of sustainable development imply (Davoudi, 2000; DETR, 1999a). The mantra of sustainability lies at the core of the regeneration agenda and is loaded with expectations of being a magic bullet for delivering 'better' cities. 
The mechanism for delivering such development is the collaborative style of planning and associated rhetoric of partnership, under which planners are recast as facilitators of development located within wider networks of stakeholders (de Magalhaes et al, 2002; DETR, 1999b; Healey, 1992; 1997; Jessop, 1994). In particular:

"multi-agency governance is now promoted as a mechanism for getting things done in the face of complexity, conflict and social change ... by [agencies] blending their resources, skills and purposes with others" (Kearns and Paddison, 2000, page 847, quoted by Raco, 2003, page 39).

As part of this shifting emphasis, regeneration has tended to be daubed in the government rhetoric of partnerships between civic and commercial bodies, and empowerment of local communities through civic discourses of inclusion (DTLR, 2001). Taken together, the collaborative mode of planning and goals of sustainable development may be said to structure the realm of urban regeneration.

\section{The problem of ambiguity}

Research has tended to suggest that the collaborative partnership approach has not delivered on the promises of sustainable regeneration in practice, identifying the ambiguity of the term 'sustainable' as a major problem. The following three critiques deploy slightly different analytic approaches, based upon research from different cities, which add some depth to how ambiguity is seen to undermine the goals of sustainability in practice.

Couch and Denneman (2000) have examined whether the goals of sustainability enshrined in strategic-level British urban policy are actually meeting the requirement for more sustainable development in practice. They address this question via the case study of the Duke Street/Bold Street redevelopment in Liverpool, a classic example of urban regeneration in a run-down mixed-use area adjoining the city centre, with a combination of derelict industrial units/houses and relatively high levels of poverty. The development was to be delivered through a collaborative planning process that centred on the creation of the Rope Walks Partnership, which included a cross-sectoral range of stakeholders (public bodies, environmental agencies, utilities, and so forth). In practice, however, this process broke down because,

"Each agency has its own agenda; its own management system; its own financial imperatives and its own priorities. The key to implementing the environmental agenda in this situation is the ability to negotiate, to search for synergies and to build coalitions and partnerships for action. Unfortunately, just as partners in coalition governments have to forfeit some of their political agenda, so, in the regeneration process, agencies have little choice but to make compromises that weaken their ability to promote sustainability" (Couch and Denneman, 2000, page 146).

In their analysis, Couch and Denneman relate this weakening of sustainability to its malleability, arguing that this ambiguity leads to the prioritising of economic aspects of development over social and environmental concerns:

"From the national to the local level there is an ambivalent attitude to sustainable development and a constant attempt to compromise and reinterpret the concept to support the aim of economic development" (page 146).

The interpretation of sustainability along purely economic lines is a common theme within the regeneration literature, and the ambiguity of the term is often depicted as enabling the economic agenda. Although disappointing, this is perhaps not greatly surprising in the context of socioeconomically disadvantaged urban areas such as Liverpool's Ropewalks. 
Later, Raco (2003) explored the dominant forms of regeneration taking place in Reading - a relatively affluent town located along the M4 corridor some thirty miles from London, which is currently undergoing significant growth. Although representing a very different socioeconomic and political context from the Liverpool Ropewalks, he found a similar bias towards the economic in a supposedly 'sustainable' regeneration programme, this time articulated through the concept of growth:

"in such places growth can be used as a focus for the formation of regimes and partnership networks of action. Alternative discourses which promote sustainable development or slower growth are, conversely, sidelined" (Raco, 2003, page 41).

A recurrent theme that emerges from these two studies of urban regeneration projects is the hijacking of sustainability agendas by economic interests. The ambiguity of the term itself is seen as a key factor in this process, as its flexibility and openness to context-specific interpretation at the local level allows dominant preexisting interests to come to the fore.

This tendency is explored further in a London-based study published in the same year, in which Rydin et al (2003) sought to examine whether new procedural arrangements such as environmental assessment, sustainability audits, and sustainability indicators were embedding sustainable development as a policy goal into policy practice. Taking a case study of urban regeneration in the London Borough of Southwark, Rydin et al argue that sustainable development was sidelined as a policy goal for the area:

"In a situation, such as that in Elephant and Castle, where there is no unified vision of sustainable development, procedures become a means whereby alternative visions for the area come into competition with each other.... Conflicting interpretations of the concept of sustainable development were shaped by these circumstances; the procedures using sustainability criteria then became carrying mechanisms for those interpretations" (2003, page 559).

Again, the ambiguity of the term is seen as problematic because it is open to partial interpretation by antagonistic stakeholders. In this case, the process did not get hijacked by economic interests but, rather, became a microcosm of preexisting local conflicts, miring the process in tensions between various groups. This situation is highly undesirable as,

"While externalised conflict between local government and groups based only in civil society or the economy may delegitimize policy and can, in some circumstances, delay policy action, internalizing conflict can be much more damaging" (Rydin et al, 2003, page 559).

In all three examples the lack of conceptual clarity surrounding the term 'sustainable' has been constructed as problematic. As a result, the language of sustainability in the tripartite form used in UK regeneration policy establishes a policy of compromise and, by implication, failure as it becomes impossible to deliver a 'sustainable' regeneration. While different in their approaches and case-study locations, these studies draw similar conclusions: the ambiguity of what sustainable regeneration actually constitutes causes problems for the process of collaborative planning, as it allows the agenda to be hijacked by partisan interests (most often economic). These conclusions are echoed more widely as Prugh et al (2000, page xiii) state rather prosaically, because sustainability "is a mule that can be hitched to many wagons, sometimes the mule is abused."

The three studies above all sought to evaluate the success with which policy aims for sustainability were being put into practice, whether between national and local levels of policy, in planning discourses, or through procedural tools such as sustainability indicators. They essentially assess whether the practice lived up to the ideal. 
This is undoubtedly an important task - the ideals are not only detached academic ideals, but self-imposed policy goals and include regulatory guidelines and checks which are intended to ensure accountability at the ground level. As a result, these procedures need to be critically appraised.

This approach does, however, seem doomed to discover failure. Inevitably falling short of the benchmarks of the triple bottom line in practice tends to engender a conceptual language of 'barriers' when examining the ambiguities inherent in how urban regeneration partnerships operate. These range from the shortcomings of political fora (Rydin et al, 2003), to the perceptual failings of practitioners (Cooper and Palmer, 1999), and the unforgiving economic realities of capitalist development (Gibbs et al, 2002). The tendency to judge the sustainability of urban regeneration projects and ultimately fail them particularly afflicts geographers, whose theoretical approaches are allied to an inbuilt disciplinary emphasis upon environmental considerations (Couch and Denneman, 2000; Hanson and Lake, 2000) - which are so often the least influential leg of the sustainability stool in practice.

This analytic tendency is itself situated within a wider conflict within the literature, in which the ideals of collaboration and the realpolitik of planning form a key tension. Academic critiques of this failure tend to focus upon the role of power relations in subverting consensual planning processes, and the subsequent failure to base decisions upon rational and technical grounds (Flyvbjerg, 1998). Within the urban regeneration literature, this has led to critiques of terms like 'partnership' and 'empowerment' as discourses that actually reinforce the power of the central state (Davies, 2002b), or presage the hegemony of partisan lobbies (Atkinson, 2002, but urban regime analyses also deploy a similar logic), as ambiguity is exploited by more powerful stakeholders to appropriate policy agendas.

As the three examples used above illustrate, the problem of ambiguity becomes apparent through the perceived failure of communicative mechanisms to achieve the policy goals of regeneration. Consensual approaches associated with collaborative planning assume that political consensus between divergent positions can be reached if the correct procedures and institutions are in place. This implicit model permeates the regeneration literature because it resides in the political processes being studied (for example, 'partnerships' and collaboration). Within this model of rational communication, the 'right' decision is ensured by the 'right' communication (Habermas, 1993). In reducing the process of sustainable urban regeneration to an ideal process of communication, however, this model predetermines the failure of the process - the ideal of sustainability will never be reached.

Within this well-worn exchange between ideal (rationalist-communicative) process and pragmatic (political) critique, ambiguity plays a key role. Seen as problematic to the achievement of consensus, it is then identified as a key area of contestation through which the ideal goals of sustainability are subverted. Both approaches fail to capture the ways in which sustainability affects how urban regeneration is actually carried out. In order to capture the difference which sustainability makes in practice, we need to frame the object of study in a different way.

\section{Communicating 'actually existing sustainabilities': a dialogic approach}

When it comes to the actual practice of regeneration there is a need to understand sustainability as a grounded phenomenon, situated in places and performed by actors and institutions, rather than as a formalised ideal. As Owens and Cowell have argued (2001, page 14), techniques and procedures are "inseparable from (contested) interpretations of sustainable development... the reality is less elegant and considerably less tidy than the metaphor." Other authors have also begun to emphasise the "actually 
existing sustainabilities" that are concerned with "actual practices rather than... guiding principles" (Krueger and Agyeman, 2005, page 411). The question then becomes one of how we can capture this dimension of sustainability in practice.

As stated above, we contend that the key to articulating actually existing sustainabilities lies in understanding the positive role that ambiguity plays in the collaborative planning process. In this section we present a reframing of ambiguity, drawing upon the dialogics of Michel Bakhtin, and then address the methodological challenges of accessing the sociopolitically embedded communicative process of collaborative planning through which regeneration occurs.

Within the literature there has been considerable debate concerning the problems of language associated with ambiguity. As Church and Young (2001, page 116) comment, "Competing understandings of sustainable development have been especially significant. Language itself has been a barrier".

Owens (1994, page 440) has suggested that a clear definition of what is meant by sustainability can result in the conflicting agendas of different interests being exposed at an early stage in the planning process, and the government has recognised the need to attend to the linguistic problems inherent within the term (DETR, 2000a). Concerns with the language of sustainability thus have some lineage, but we want to turn specifically to the Bakhtinian school of dialogics as questions of ambiguity and meaning are central to this body of work. Michel Bakhtin and his fellow workers in the Bakhtin circle wrote in the first half of the 20th century, but much of their work was only translated into English in the 1980s and 1990s. Although this work has relevance to a range of philosophical, literary, and sociolinguistic fields, it is their early work on the role of language as a form of social meaning-making that holds most relevance to the questions raised in this paper.

The central tenet of Bakhtin's social theory of communication is that meaning is created through dialogue between actors, grounding the meaning of words entirely in their situated social usage (for a detailed account see Shotter and Billig, 1998). This is a particularly useful approach to understanding a relatively unfixed word such as 'sustainability', which is recent in its origin (at least in the policy sense of 'sustainable development') and intended to be context specific. Meaning is created through dialogue between parties which are unavoidably situated in different social contexts, with differing histories and experiences; hence meanings are always partially shared and partially ambiguous (Holquist, 1990). This led one of Bakhtin's peers, Valentin Voloshinov (Voloshinov and Bakhtin, 1986, page 86), to suggest that words are best conceived of as 'shared territories' between social actors: with enough meaning in common to facilitate communication, but at the same time partially ambiguous.

Ambiguity, then, is an effect of the unique experience of different actors, situated within different space-times. This unique position gives rise to a dialogic relation that defines both the self and the other. The meaning of words is established by common social usage; as such, "they do not have any underlying invariant fixed meanings ... [they] are meaning potentials open to different interpretations" (Lahteenmaki, 1999, page 90). This is not, however, to imply the "simplistic pluralism that some of Bakhtin's more liberal readers have wanted to see in his work" (Holquist and Liapunov, 1990, page xxiii). The relation between actors is never given, but is achieved through the activity of what Bakhtin calls 'architectonics', where "Every word performs a twofold function insofar as it directs my projection of myself onto the other as well as brings him [sic] to completion" (Bakhtin, 1990b, page 27). The two-fold quality of the word is manifest in sustainability, as actors both project their own agenda, but seemingly also reflect upon its meaning from the point of view of others. This formulation introduces the idea of identity, an aspect of the multistakeholder regeneration process that can be 
oversimplified in research. Within these processes, the efforts of actors to maintain their own identities in the mirror of others are critically dependent upon the word as a shared territory. As Bakhtin states, "we evaluate ourselves from the standpoint of others..." (1990b, page 15). This search for completion is never consummated, but always unfinalised, constituting the basis for a theory of creativity (discussed later in the paper).

These formulations reverberate with a range of concepts from other theoretical registers, and prompt some reflection before moving on. Foucault's model of discourse (see, for example, Foucault, 1972; 1980) casts ambiguity as a source of 'micro-resistance', operating at the edges of hegemonic discourse (Dreyfus and Rabinow, 1982; Raulet, 1983). Habermas coins the idea of 'reciprocal empathy' to designate the capacity of different stakeholders to put themselves in the position of others, but again this is not a core element of the communicative process. ${ }^{(1)}$ It is necessary to place ambiguity at the core of the analysis as an unavoidable and, indeed, desirable factor in order to capture the positive impacts of sustainability on the process and to avoid it being merely problematised as a consequence or by-product of communicative failure. Dialogics remains purely on the level of immanence, concerned with the relation between actions and meaning, or 'answerability' (Bakhtin, 1990a). ${ }^{(2)}$ This is undoubtedly a weakness in terms of the utility of dialogics as a general sociopolitical theory as it neglects the analysis of institutional power and hegemony, but makes it well suited to our current purposes (we return to the validity of different communicative approaches to urban regeneration in the conclusion).

We have dealt with two aspects of identity: that of the self to the self; and that of the self to the other. The theory of dialogics also articulates a relation between the self and the object. This is again important within the context of regeneration and planning more generally, in which the development constitutes a central object. This object is particularly important within the context of collaborative planning, where partnerships are formed around it. Speaking on objects, Bakhtin states:

“... it is our relationship to it [the object] that determines an object and its structure, not conversely..." (1990b, page 5).

More relevantly to the notion of developments:

"My relationship to each object within my horizon is never a consummated relationship; rather it is a relationship that is imposed upon me as a task-to-be-accomplished, for the event of being, taken as a whole, is an open event.... Objects do not surround me... but rather stand over against me... (Bakhtin, 1990b, page 98, original emphases).

This understanding of the object as 'becoming', rather than given, takes on a literal sense in regeneration planning, where the project is literally in the process of 'becoming real', and 'stands over against' the stakeholders as their 'task to be accomplished'.

(1) It is worth noting that the positions outlined above are to some degree caricatured, and that this simplification is used to emphasise the opposition that is set up between them. There are two justifications for taking this approach (beyond that of rhetoric). Firstly, the polarisation of these positions within the planning literature between political and rational has been widely noted (Murdoch, 2006), and it is the use of these theoretical registers (both by those studying and by those practising urban regeneration) that we are critiquing, rather than the richly layered and complex theoretical tradition that underpins each. Secondly, while these traditions do offer more nuanced ways to conceptualise difference and, especially, political difference, we wanted to develop an alternative terminology that is founded expressly upon the creative potential of ambiguity.

(2) This is not entirely antithetical to theories of social action based upon performativity, as Bakhtin's (1993) understanding of language is based upon a materialistic philosophy. While this is an interesting aspect of his theoretical framework, it is left implicit within this paper. 
This understanding resonates with the work of other authors who have sought to capture the emergent and provisional character of the built environment, rather than taking its uncontested materiality for granted (Jenkins, 2002; Lees, 2002). The word is critical in bringing the object to completion for various actors, and in imparting meaning to the process of development.

Drawing upon Bakhtin's dialogic theory of the word as a 'shared territory', the conception of sustainability is not only 'shared' in terms of content, but is also shared through a relational identity between actors in the project. This has a number of methodological implications when we attempt to capture these processes in practice. At the most obvious level, we wanted to capture how the word 'sustainability' was actually used and understood. Therefore, our research design followed others in the field in focusing upon how actors deployed discursive practices to frame their own involvement (see, for example, Astleithner et al, 2004; Murdoch, 2006; Raco, 2003; Whatmore and Boucher, 1993 for discursive approaches to regeneration and planning more generally). Accordingly, we used qualitative research techniques, conducting twenty semistructured interviews (Gillham, 2000) with a range of stakeholders, and longitudinal interviews with three key actors to cover the changing attitudes to the development and sustainability over the course of four years. A series of site "walkovers' were also undertaken with residents to explore personal attachments to the site and the meanings attached to the new project, although this material is largely used to provide background within the context of this paper.

Questions focused upon how actors understood sustainability, both personally and professionally, and how this understanding had evolved over the course of the project. We tried to tease out examples of how meaning was attached to the word, particularly through the use of real-world examples of sustainability by interviewees. Our analysis differs in that it focuses not only on what actual meanings were attached to the term (for example, predominantly social, economic, or longevity), but also on how it was deployed to bring meaning to the self, the other, and the object. In other words, we wanted to excavate the role which sustainability played as a shared territory for the urban regeneration project as it unfolded. Data were coded according to these themes, and discourse analysis was used to highlight the role of sustainability in the process of meaning making and relational identity formation (see Fairclough, 2003; Van Dijk, 1985).

\section{Sustainability in practice: the Park Central development}

Park Central is a 43-acre redevelopment project being undertaken on part of a former council estate, Lee Bank, in central Birmingham. The scheme is an exemplar of the complex, multiagency, partnership arrangements which characterise contemporary regeneration practice. Following a lengthy campaign by local residents, Lee Bank and four neighbouring estates were transferred into the hands of a newly established registered social landlord, the Optima Community Association, in 1999. Only the housing land was transferred to Optima, however: the remainder, in particular the large area of public open space in Lee Bank, remained in the hands of Birmingham City Council. It was clear, therefore, that any redevelopment scheme on the estate would require the active involvement of the local authority beyond the normal planning process.

In collaboration with property consultants GVA Grimley, Optima and the City Council put together a large land parcel, combining Lee Bank's park and land released by demolishing 1960s housing units. The project went out to tender and Crest Nicholson were eventually chosen as the developers for the site. Their masterplan, produced by Gardner Stewart Architects, formed the basis for Park Central-a ten-year project, the first completed units of which were occupied in 2004. 
This brief summary of the project's history gives no sense of the messy process of negotiation and deal making that underpins the business of actually getting buildings built on the site. Clearly, the different agents were involved in the project for different reasons, but, in rhetoric at least, there was a sense of a common purpose, something that was most coherently expressed by Crest's Project Coordinator:

"I think everybody's got the same goal. And the same goal is that we actually construct accommodation that people want to live in that will be, in the true sense of the word, 'sustainable'..." (Paul Meade, 27 September 2004, original emphasis).

There is no doubt that some of the negotiations between actors over matters of detail were, at times, somewhat fraught. This narrative of sustainability has, however, clearly been a powerful force in producing the sense of common purpose drawing the partnership together. This 'true sense' of sustainability that is helping to bring the participants together is not, however, something which is unambiguously understood.

Parks offer an interesting arena for contesting different notions of sustainability - a green space perceived as people friendly is not necessarily the same thing as one perceived to be ecofriendly/biodiverse (Burgess et al, 1988). The park area of Lee Bank has been significantly reduced as part of the redevelopment, something one might cynically suggest was ironic given the name chosen for the redevelopment. A survey of residents carried out early in the process of Optima taking over the estate, however, showed significant fear of crime relating to the Lee Bank park. This was taken as a mandate to make some dramatic changes. The park did contain a large number of mature trees, almost all of which have been cut down as part of the replanning. The city council's landscape architect working on the project suggested that there had originally been no clear planting strategy for these trees-that the site tended to receive whatever saplings the parks department had a surplus of in any given year. The new park is planned to have a much higher proportion of native tree species, as well as a small wildflower meadow, perhaps offering the new park a little more ecological credibility (Jonathan Webster, 25 August 2005).

Residents had a strong input into designs for the park and Crest's Project Director for Park Central suggested that the amount of play equipment requested had restricted their flexibility to take a more biodiversity-driven approach to the design. This said, however, Crest wanted the new West Park

"to be a little bit like a London square. Pretty informal. Big trees around it. Park railings with plants growing through the railings, and a place to sit and have a picnic" (Stephen Boid, 4 August 2004, original emphasis).

Aesthetics were, therefore, crucial. The hope was that people working in the office quarter to the north of Park Central would consider coming to the new park to have lunch-something which would not have happened when the area was still an extremely run-down council estate. The question of long-term viability seems to be paramount to all the actors, a sentiment summed up by the landscape architect:

"I'll be distraught if after 20 or 30 years they have to rip it all up again, that's the real test! That is the key to sustainability" (Jonathan Webster, 25 August 2005).

Although most of the interviewed individuals from these organisations referred, at least in passing, to notions of sustainability without being prompted, each was directly asked what sustainability meant to them. Crest's Stephen Boid emphasised the environmental issues, seeing sustainability as a goal to be strived for:

"I think like all developers we will reluctantly be kicked into sustainability. None of us like paying the price. It's happening, it will happen. On the later phases, the dwellings will be more sustainable than on the earlier phases-that's just progress..." (Stephen Boid, 4 August 2004, original emphasis). 
In this context, unsurprisingly given the nature of the development industry, the cost implications of environmental measures were paramount. In addition, Stephen Boid stressed how Crest had recently been restructuring around urban regeneration, including issues of sustainability, this being perceived to be good business sense given the current state of the development market. In a sense, therefore, we can see the strategic deployment of the sustainability concept in response to (state) policy goals. It should not be thought, however, that the profit motive is solely the preserve of developers. Optima's Development Manager commented that

"there's no point in us putting a shopping precinct in unless there's demand for shops - it's not going to be sustainable. The last thing we want here is an area that's going to be a ghost town. There's just no point" (Dave Thompson, 9 August 2004).

The sustainability discourse here has spilled over into questions of financial viabilityquestions which plagued postwar council estates. From Optima's point of view, however, the focus is on ensuring that household incomes in the area be at a level sufficient to sustain the services that the community requires, rather than the community being needed to sustain the service providers.

When asked directly about sustainability, Thompson commented that "Birmingham City Council have been pushing the sustainability thing - they want a sustainability statement now with every planning application." In common with Boid, he initially discussed this very much in terms of environmental considerations-groundwater sources, drainage systems, heating systems, and so forth. Matters soon returned to financial issues, however, as Thompson noted the impact of the Housing Corporation's changed rules on Optima's rental structures and the need for efficient heating and good insulation to minimise costs for the tenants. Again, sustainability was being seen very much through the lens of the organisation's core interests - in Optima's case, the well-being of the (low-income) community it was set up to serve.

The planning officer responsible for Park Central made it clear that the interest in sustainability was something that the politicians on the City's Development Control Committee were keen to engage with, though not necessarily in a particularly focused way ("There's lots of lip service to sustainability..."). Commenting on the Park Central development itself, he suggested:

"It is a sustainable location in that its only a ten-minute walk to the city centre, people who don't know the city are only five minutes from the Bullring. They couldn't do any better. In fact in terms of sustainability, this is what most people think of" (Rob Wells, 23 August 2004).

The rather narrow definition drawn here is interesting not least because it is the kind of 'sustainability' that few people could have any objection to. Under this popular definition, the various agents in the process could feel positive about the development because its mere location gave it a certain sustainable cachet. Interestingly, when Wells himself was asked what the key to sustainability was, he replied:

"The key is achieving mixed use. Essentially the development will be sustainable if people don't want to leave."

Environmental concerns were thus pushed into the background, behind a much more pragmatic concern with the residential/community function of the site.

The environmental side of sustainability was certainly to the fore where it was a matter of compliance - the building regulations being a prime example. In other areas, however, environmental sustainability is a little more negotiable. A decision was taken at a very early stage not to use a sustainable drainage system (SuDS) on the site. This was in part at least because certain SuDS techniques require fairly large areas of open space-problematic given the competing demands already being placed on the park. Park Central's drainage consultant explained that measures had been put in place to 
ensure that the surface-water discharges would not increase as a result of the new scheme ("it's sustainable inasmuch as that"), but went on to comment:

"I personally have an interest in SuDS. It would have been nice on a scheme of this size to perhaps have incorporated a few other features. But I fully understand the commercial side of it as well. And you win no brownie points for pushing that to its extreme. Because we're not being forced by anybody else" (Steve Martin, 8 October 2004).

With no pressure from the Environment Agency to use the redevelopment as an opportunity to reduce the load on conventional drains, a SuDS type approach was simply not a priority. Even with a personal interest in these kinds of systems, no consultant would push the matter if it were not a matter of compliance and was not a priority for the client.

\section{Sustainability as a shared territory}

It is not our intention to criticise this least-compliance approach to certain aspects of environmental sustainability. Rather, we want to highlight the fact that a less constrained definition helped create a common ground for organisations whose core concerns can be quite different. A general rhetoric of sustainability provides an atmosphere in which, for example, the drainage consultant could lobby his clients to add low-level SuDS, such as porous paving (which has fairly minimal cost/space implications), at a later stage in the scheme. This may not be an environmental ideal, but the sustainability discourse has created a space for compromise. Similarly, Optima's Director of Property could declare:

"sustainable communities is where I come from. You could have an environmental sustainability which talks about the green agenda. Which is good, but it's not totally for me. I want a neighbourhood that works, if you see what I mean" (Dennis Pearce, 26 October 2004).

This kind of understanding might not satisfy the deepest-green ecologist, but it indicates that other aspects of sustainability are not completely ruled out even when they are not part of the actor's core concerns.

So far we have focused on the different meanings which actors place on sustainability, arguing in common with other authors that they are relatively disparate. But how does this ambiguity function in a positive way to create a shared territory? As outlined above, under a dialogic interpretation, words perform a twofold function in establishing both the identity of the self and that of the other. This twofold quality of the word is manifest in sustainability, as actors both projected their own agenda but seemingly also reflected upon its meaning from the point of view of others. Two becomes three as, when asked about sustainability, the key stakeholders define sustainability personally, in relation to the needs of another group, and in terms of the development itself. As table 1 shows, this is reflected in the threefold semantic structure of a number of responses: self (first person pronoun, 'I'); other (third person plural pronoun, 'they'); and project (third person neuter, 'it').

Sustainability grounds a threefold relation, between self, other, and object, and it is this dialogic process that creates the shared territory around which stakeholders in the project coalesced. There is a wealth of relational politics in the way in which sustainability talk establishes the identities of those stakeholders involved. This is critical in explaining how organisations with quite different philosophies/priorities managed to come together and negotiate a redevelopment project which, although not perfect, has achieved the goals of each of them. Undoubtedly this success is also due to the particularly talented and pragmatic group of people involved, but the ways in which sustainability has been talked about constitute a critical factor which, in creating a 
Table 1. The semantic structure of 'sustainability speak'.

\begin{tabular}{ll}
\hline Relation & Example quotes \\
\hline Self & " $\ldots$ sustainable communities is where I come from." \\
& "I personally have an interest in SuDS ... . But I fully understand the \\
commercial side of it as well." & "I think like all developers ..." \\
& "we're not being forced by anyone else" \\
Other & "they want a sustainability statement" \\
& "They couldn't do any better. In fact in terms of sustainability, this \\
& "Is what most people think of." \\
Object & again, that's the real test!" \\
& "it's sustainable if people don't want to leave." \\
& "It's happening, it will happen."
\end{tabular}

Shared territory "I think everybody's got the same goal."

shared territory, has produced a long-term regeneration project which has kept all of its major stakeholders on-board while radically transforming social, economic, and environmental standards on the estate. In terms of capturing the actually existing effect of sustainability on this regeneration process, it is not what was meant by sustainability that counts, but how it was deployed. Ambiguity, far from being problematic, therefore, was essential to the communicative process. Sustainability had a profound effect upon the course of the development, even if it was not in terms of what policy frameworks and guidelines might have intended.

\section{Ambiguity and creativity}

So far, we have sought to demonstrate the importance of ambiguity in allowing sustainability to function as a 'shared territory' between different stakeholders throughout the regeneration process. The notion of the shared territory as a ground for polyvocal dialogue also allows unexpected or creative outcomes to emerge. In the following section we outline the relation between ambiguity and creativity in dialogic theory, and then provide an example from the regeneration process.

Ambiguity, or meaning potential, was fundamental to Bakhtin's conception of creativity, or what he called 'novelness' [Holquist (1990) argues that this concept runs through Bakhtin's work]. While different actors are able to share meanings to an extent, their unique position will always create partially different interpretations. This was fundamental to the inherent surprisingness of human behaviour-its unfinalisability. In his analysis of Dostoevsky, Bakhtin argues that he was the first author in the modern European tradition to surrender the author's 'essential surplus' of vision, by unfolding the story through the voices of multiple characters (1984). In doing so, he placed the author on the same level as his characters, knowing no more about them at any given moment than would be possible for the characters themselves to know. This form of writing - polyphony, using more than one voice-establishes a new relation between the author and the characters. Surprise is, therefore, not accidental but essential to the unfinalisability that lends this process its creativity or novelness.

Returning to the Park Central example, it is possible to identify how novel responses to the regeneration challenge emerged from the shared territory of sustainable development. The Estates Renewal Challenge Fund (ERCF), under which the redevelopment was initially financed, was intended to pay for small-scale demolition works and major 
refurbishment programmes. Even before funding was secured, Birmingham City Council had negotiated a much higher proportion of demolition. With Optima formed to run the site, the original plan for demolition and piecemeal land sales was scrapped and, working in association with consultants GVA Grimley, Optima envisaged a much more comprehensive scheme in partnership with a single developer. With Crest Nicholson winning the tender for the scheme, the final designs for the area changed quite radically as Crest brought in its own architects. The scheme now being built reflects a shared vision that developed between the different partners involved, but is completely different from the kind of scheme originally envisaged under the ERCF mechanism. The plans for the kind of physical landscape being produced may have changed, but at each stage the expressed desire to produce a sustainable development has been consistent among the different partners involved.

The coherent development of the Park Central site that was critical in delivering a vision of holistic sustainability was a largely unexpected outcome of the regeneration process. In order to understand how this plan emerged from the ambiguities surrounding the concept of sustainability in practice, it is worth considering the communicative terms and framework between the actors. The regeneration process was characterised by interaction between three key players-Optima, Crest, and the city council - supplemented by the involvement at various stages of other organisations and suborganisations such as GVA Grimley and the parks department, as well as the ongoing engagement of local residents. The differing interests, remits, and power of each of these stakeholders lent the process a degree of complexity, which meant that each stage of the development (planning, tendering, designing, and finally building) was characterised by an unusually high level of face-to-face dialogue between these stakeholders. This complexity demanded a form of engagement that would allow for multiple interests to be heard, and was crucial in opening up spaces of dialogue through which a more novel and context-specific notion of sustainability could be developed. Indeed, weekly meetings were held at the site from the design stage onwards. If one of the key players had been in full (financial and political) control of the site, this process would not have happened. Similarly, a complete and unambiguous vision of sustainability would have resulted in a more limited development.

Viewing sustainability as a 'shared territory', simultaneously held in common and idiosyncratic, suddenly makes ambiguity not only intelligible but also desirable to the communicative process as the fount of creativity. Rather than a failure of rational communication, or a marginalised act of resistance in the face of hegemonic power interests, ambiguity is critical in facilitating novel forms of governance and design that are so necessary to the government's aims of 'creating' socially, culturally, and ecologically vibrant populations (ODPM, 2003; 2004).

This understanding of communication places ambiguity rather than rationality centre-stage, as it is fundamental to generating creative outcomes. As Holquist (1990, page 87) puts it:

"novelness is the name Bakhtin gives to a form of knowledge that can most power-

fully put different orders of experience-each of which claims authority on the basis of its ability to exclude others - into dialogue with each other."

Relating this mode of understanding back to the stakeholder process of urban regeneration, it is also possible to see how this mode of communicative understanding can accommodate the 'messiness' of real-world situations. The dialogic model allows the story to unfold through the voices of multiple characters, and this polyvocal politics may be better suited to interpreting the context-specific low politics of decentred Rhodesian governance. Such an understanding also raises theoretical and methodological 
implications for how we study these processes. Indeed, in embracing theories of identity formation we are led into the fields of performance and ethnography, and methods such as video diaries and participant observation ${ }^{(3)}$ constitute exciting potential avenues of research in this area in future.

\section{Conclusions}

Despite its broad definition, the concept of sustainability has become central to regeneration policy in the UK. Given that regeneration is characterised by multiagency partnerships, it is entirely possible that the different actors in any given regeneration scheme might be working to quite different ideals when attempting to realise the vision of a sustainable development. This ambiguity can be problematised as a failure of communication between the different actors, or simply seen as a kind of resistance against a hegemonic discourse. We have argued, however, that it is possible to read ambiguity in a more positive light: not merely as something that is unavoidable because individuals are all positioned differently, but as something which is actually desirable in order to facilitate a creative response. Indeed, government policy repeatedly advocates creative and innovative approaches to the building of sustainable communities.

The concept of dialogue is well suited to understanding urban regeneration, as the notions of dialogue and ambiguity capture the unavoidably polyvocal character of the process without reducing the outcome either to consensus or to domination. Groups are, by necessity, positioned differently with respect to the goals of regeneration. It is precisely because they may not have quite the same thing in mind when they talk about 'sustainability' that the term provides a glue holding the actors and organisations together, framing spaces for innovation. Within this conception, however, it is important to distinguish between what is meant by sustainability and how the term is deployed to establish relational identities between stakeholders. We have argued that it is the first of these senses that renders ambiguity problematic, whereas the second reveals its positive effects.

Obviously, we are not suggesting that political critiques of the ambiguity inherent to the concept of sustainability should instantly be negated - far from it. Sustainability is a highly contested term, with very real political effects, and will remain so. Critiques of power and politics are essential to understanding why projects so often fail to achieve their goals in practice. It is necessary to be sensitive to the dangers of championing urban regeneration projects and the actors involved as paragons of sustainability and community building. The development of Park Central on a former inner city council estate was not perfect, with dissenting views aired by some local residents, environmental groups, and others. These are important stories that need to be told in order to capture the political forces that frame regeneration as a process of contested urban transformation; they are stories that have been told elsewhere (Jones, 2004; Jones and Evans, 2006).

(3) Of course, these methodological approaches are potentially problematic because of the difficulty of access. It is one thing to ask for an hour of a professional's time, but quite another to suggest following them around - potentially videoing every minute of their working day for a protracted period of time. As a result, these methods were felt to be unsuitable within the limited scope of the research project upon which this work was based. The role of mechanisms like the ESRC-CASE $\mathrm{PhD}$ studentships in allowing academic researchers to enter into their own, more sustained, dialogic relationships with those whom they study would be particularly suited to the demands of this type of research. 
The standard critique of urban regeneration tells a story of its capture by neoliberal principles of market efficiencies, entrepreneurial communities, and resource exploitation. Where regeneration schemes are perceived as overly skewed toward economic aims there is a tendency to view the sustainability agenda as having failed. This is only part of the story. Because the language of sustainability dominates the policy agenda, this creates a space for compromise between the different agents which the holistic/partnership approach to regeneration demands. In the case of Park Central, neither the economic agenda of the developer nor the social agenda of the community association dominated-sustainability as a concept allowed them to identify themselves against one another, but in common relation to the development itself. This process of identification led to a development vision that was quite different from how the different sides originally envisaged the project. Rather than focusing on language as a barrier, conceptualising the word as shared territory reflects how sustainability can generate innovative developments.

In this paper we have not argued that sustainability has been achieved, but rather that sustainability cannot be 'achieved' in any total sense. We started with the contention that, while sustainability is widely critiqued, contemporary urban regeneration would look different without it and that this difference is one that our current modes of analysis tend to miss. The model we have explored in this paper focuses on capturing the actually existing practices of sustainability, disengaging from the language of failure and 'barriers' that permeates this area, to experiment with the creative dimension of ambiguity that characterises the actual practices of sustainability. By focusing upon sustainability in practice, it has been possible to capture some of the ways in which this difference is made.

As an experimental endeavour, the paper opens up a series of potential further debates. How do different communicative approaches to urban regeneration capture different aspects of what is an inherently multifaceted political process? Our understanding of communication places ambiguity rather than rationality or politics centre-stage, as it is fundamental to generating creative outcomes. Further work is needed to outline how the analysis offered here might fit into more traditional institutional and political accounts of planning. This task is of particular importance in situating our own, rather positive, account of ambiguity and the regeneration process in terms of broader poststructural approaches to planning. Perhaps the most important element of this approach to communication in urban regeneration is to offer an alternative to the prevailing downbeat accounts of failure: instead, seeking a way to work with these processes and those involved in them, rather than outside and apart from them.

\section{References}

Astleithner F, Hamedinger A, Homan N, Rydin Y, 2004, "Institutions and indicators - the discourse about indicators in the context of sustainability" Journal of Housing and the Built Environment 19 7-24

Atkinson R, 2002, "Rebuilding community: policy and practice in urban regeneration" Urban Studies $392555-2556$

Bakhtin M, 1984 [1929] Problems of Dostoevsky's Poetics (University of Minnesota Press, Minneapolis, MN)

Bakhtin M, 1990a, "Art and answerablility", in Early Philosophical Essays by M. M. Bakhtin Eds M Holquist, V Liapunov (University of Texas Press, Austin, TX) pp 4-256

Bakhtin M, 1990b, "Author and hero in aesthetic activity", in Early Philosophical Essays by M. M. Bakhtin Eds M Holquist, V Liapunov (University of Texas Press, Austin, TX) pp 4-256

Bakhtin M, 1993 [1920 - 24] Toward a Philosophy of the Act (University of Texas Press, Austin, TX)

Bruff G E, Wood A P, 2000, "Local sustainable development: land-use planning's contribution to modern local government" Journal of Environmental Planning and Management 43 519-539 
Burgess J, Harrison C, Limb M, 1988, "People, parks and the urban green: a study of popular meanings and values for open spaces in the city" Urban Studies $25455-473$

Carley M, Christie I, 1992 Managing Sustainable Development (Earthscan, London)

Church C, Young S, 2001, "The United Kingdom: mainstreaming, mutating or expiring?", in Sustainable Communities in Europe Ed. W Lafferty (Earthscan, London) pp 107-129

CLG, 2006, "Partnerships and Local Area Agreements", Department for Communities and Local Government, http://www.communities.gov.uk/index.asp?id=1161632

Cooper I, Palmer J, 1999, "Review of EPSRC's Sustainable Cities Programme" Planning Practice and Research $14125-132$

Couch C, Denneman A, 2000, "Urban regeneration and sustainable development in Britain" Cities $17137-147$

Davies A R, 2002a, "Power, politics and networks: shaping partnerships for sustainable communities" Area 34190 - 203

Davies J, 2002b, "The governance of urban regeneration: a critique of the 'governing without government' thesis" Public Administration $80301-322$

Davoudi S, 2000, "Sustainability: a new 'vision' for the British planning system" Planning Perspectives 15123 - 137

de Magalhaes C, Healey P, Madanipour A, 2002, "Assessing institutional capacity for city centre regeneration: Newcastle's Grainger Town", in Urban Governance, Institutional Capacity and Social Milieux Eds G Cars, P Healey, A Madanipour, C de Magalhaes (Ashgate, Aldershot, Hants) pp $45-64$

DETR, Department of the Environment, Transport and the Regions 1999a Urban Task Force Prospectus: Our Towns and Cities: The Future-Delivering an Urban Renaissance (The Stationery Office, London)

1999b A Better Quality of Life: A Strategy for Sustainable Development for the UK (The Stationery Office, London)

2000a Our Towns and Cities: The Future (The Stationery Office, London)

2000b Towards a Language of Sustainable Development (The Stationery Office, London)

Dreyfus H, Rabinow P, 1982 Michel Foucault : Beyond Structuralism and Hermeneutics (Harvester, Brighton, Sussex)

DTLR, 2001 Planning: Delivering Fundamental Change Department of Transport, Local Government and the Regions (The Stationery Office, London)

Fairclough N, 2003 Analysing Discourse: Textual Analysis for Social Research (Routledge, London)

Flyvbjerg B, 1998 Rationality and Power (University of Chicago Press, Chicago, IL)

Foucault M, 1972, The Archaeology of Knowledge (Pantheon Books, New York)

Foucault M, 1980 Power/Knowledge: Selected Interviews and Other Writings 1972 - 77 (Pantheon Books, New York)

Gibbs D, Jonas A E G, 2000, "Governance and regulation in local environmental policy: the utility of a regime approach" Geoforum $31299-313$

Gibbs D C, Longhurst J, Braithwaite C, 1998, “'Struggling with sustainability': weak and strong interpretations of sustainable development within local authority policy" Environment and Planning A $301351-1365$

Gibbs D, Jonas A, While A, 2002, "Changing governance structures and the environment: economy-environment relations at the local and regional scales" Journal of Environmental Policy and Planning $4123-138$

Gillham B, 2000 The Research Interview (Continuum, New York)

Gutes M C, 1996, "The concept of weak sustainability” Ecological Economics 17 147- 156

Habermas J, 1993 Justification and Application: Remarks on Discourse Ethics (Polity Press, Cambridge)

Hanson S, Lake R, 2000, "Needed: geographic research on urban sustainability" Economic Geography $761-3$

Healey P, 1992, "Planning through debate: the communicative turn in planning theory" Town Planning Review 63143 - 162

Healey P, 1997 Collaborative Planning: Shaping Places in a Fragmented Society (Macmillan, London)

Holquist M, 1990 Dialogism: Bakhtin and His World (Routledge, London)

Holquist M, Liapunov V (Eds), 1990 Art and Answerability: Early Philosophical Essays by M. M. Bakhtin (University of Texas Press, Austin, TX)

Jamieson D, 1998, "Sustainability and beyond" Ecological Economics 24183 - 192

Jenkins L, 2002, "Geography and architecture: 11, rue du Conservatoire and the permeability of buildings" Space and Culture $5222-236$ 
Jessop B, 1994, "Post-Fordism and the state", in Post-Fordism: A Reader Eds A Amin, M Malden (Blackwell, Oxford) pp $251-279$

Jones P, 2004, "Historical continuity and post-1945 urban redevelopment: the example of Lee Bank, Birmingham, UK” Planning Perspectives 19365 - 389

Jones P, Evans J, 2006, "Urban regeneration, governance and the state: exploring notions of distance and proximity" Urban Studies $\mathbf{4 3} 1491$ - 1509

Kearns A, Paddison R, 2000, "New challenges for urban governance: introduction to the review issue" Urban Studies 38 845-850

Krueger R, Agyeman J, 2005, "Sustainability schizophrenia or 'actually existing sustainabilities?' Toward a broader understanding of the politics and promise of local sustainability in the US" Geoforum 36410 - 417

Lahteenmaki M, 1999, "On meaning and understanding: a dialogical approach" Dialogism 174-91

Lees L, 2002, "Rematerializing geography: the 'new' urban geography" Progress in Human Geography $26101-112$

Mebratu D, 1998, "Sustainability and sustainable development: historical and conceptual review" Environmental Impact Assessment Review 18493 - 520

Murdoch J, 2006 Post-structuralist Geography (Sage, London)

Newman J, 2001 Modernising Governance: New Labour, Policy and Society (Sage, London)

ODPM, Office of the Deputy Prime Minister, London 2003 Sustainable Communities: Building for the Future (The Stationery Office, London) 2004 Consultation Paper on Planning Policy Statement 1: Creating Sustainable Communities 2005a Sustainable Communities: Homes for All Cm 6424 (The Stationery Office, London) 2005b Planning Policy Statement 1: Delivering Sustainable Development

Owens S, 1994, "Land, limits and sustainability-a conceptual-framework and some dilemmas for the planning system" Transactions of the Institute of British Geographers, New Series 19 $439-456$

Owens S, Cowell R, 2001, "Going crisply to damnation? Challenging the metaphor of the 'toolkit", Eg Magazine $12-14$

Owens S, Cowell R, 2002 Land and Limits: Interpreting Sustainable Development Within the Planning System (Routledge, London)

Pezzoli K, 1997, "Sustainable development: a transdisciplinary overview of the literature" Journal of Environmental Planning and Management 40549 - 574

Pierre J (Ed.), 2000 Debating Governance (Oxford University Press, Oxford)

Pope J, Annandale D, Morrison-Saunders A, 2004, "Conceptualising sustainability assessment" Environmental Impact Assessment Review 24 595-616

Priemus H, 2005, "How to make housing sustainable? The Dutch experience" Environment and Planning B: Planning and Design $325-19$

Prugh T, Constanza R, Daly H, 2000 The Local Politics of Global Sustainability (Island Press, Washington, DC)

Raco M, 2003, "Assessing the discourses and practices of urban regeneration in a growing region" Geoforum $3437-55$

Raulet G, 1983, "Structuralism and post-structuralism: an interview with Michel Foucault" Telos $55195-211$

Rhodes R, 1997 Understanding Governance: Policy Networks, Governance, Reflexivity and Accountability (Open University Press, Milton Keynes, Bucks)

Roseland M, 2000, "Sustainable community development: integrating environmental, economic, and social objectives" Progress in Planning 54 73 - 132

Rydin Y, 1998, "Land use planning and environmental capacity: reassessing the use of regulatory policy tools to achieve sustainable development" Journal of Environmental Planning and Management $41749-765$

Rydin Y, Holman N, Hands V, Sommer F, 2003, "Incorporating sustainable development concerns into an urban regeneration project: how politics can defeat procedures" Journal of Environmental Planning and Management 46545 - 561

Shotter J, Billig M, 1998, "A Bakhtinian psychology: from out of the heads of individuals and into the dialogues between them", in Bakhtin and the Human Sciences: No Last Words Eds M Bell, M Gardiner (Sage, London) pp 3-29

Stoker G (Ed.), 2000 The New Politics of British Local Governance (Macmillan, Basingstoke, Hants)

University of Aberdeen and Kevin Murray Associates, 2004 Towards More Sustainable Places: Sustainable Places, Partnership Working and Regeneration Skills (Turner Townsend/The RICS Foundation, London) 
Van Dijk T (Ed.), 1985 Handbook of Discourse Analysis. Volume 4: Discourse Analysis in Society (Academic Press, London)

Voloshinov V, Bakhtin M, 1986 [1929] Marxism and the Philosophy of Language (Harvard University Press, Cambridge, MA)

WCED, 1987 Our Common Future World Commission on Environment and Development (Oxford University Press, Oxford)

Whatmore S, Boucher S, 1993, "Bargaining with nature: the discourse and practice of environmental planning gain” Transactions of the Institute of British Geographers, New Series 18 166-178

Whitehead M, 2003, "(Re)analysing the sustainable city: nature, urbanisation and the regulation of socio-environmental relations in the UK" Urban Studies 40 1183-1206 
Conditions of use. This article may be downloaded from the E\&P website for personal research by members of subscribing organisations. This PDF may not be placed on any website (or other online distribution system) without permission of the publisher. 